\title{
Status 2 Patients Had Poor Prognosis Without Mechanical Circulatory Support
}

\author{
- Indications for Device Implantation -
}

Teruhiko Imamura, MD; Koichiro Kinugawa, MD, PhD; Masaru Hatano, MD; Takeo Fujino, MD, PhD; Toshiro Inaba, MD; Hisataka Maki, MD, PhD;

Osamu Kinoshita, MD, PhD; Eisuke Amiya, MD, PhD; Kan Nawata, MD, PhD;

Atsushi Yao, MD, PhD; Shunei Kyo, MD, PhD;

Minoru Ono, MD, PhD; Issei Komuro, MD, PhD

\begin{abstract}
Background: Indication for mechanical circulatory support (MCS) has been a matter of debate in less sick status 2 patients.

Methods and Results: Data were obtained from 183 consecutive patients assigned to stage D heart failure (HF) who were evaluated by the institutional review board of the University of Tokyo Hospital and then listed for heart transplantation as status 1 or 2 of the Japan Organ Transplant Network. Patients with status $2(n=38)$ had a prognosis as poor as those dependent on inotropes $(n=54)$ or MCS ( $n=91 ; P=0.615$, log-rank test), and only 4 of them had eventual ventricular assist device (VAD) implantation (10.5\%). Patients who eventually received VAD ( $n=92)$ had better 4-year survival than those without MCS among status 1 and 2 ( $P=0.030$, log-rank test). On Cox regression analysis plasma B-type natriuretic peptide $(B N P)>740 \mathrm{pg} / \mathrm{ml}$ was the only significant predictor for 4-year survival among the status 2 group ( $P=0.014$; hazard ratio, 8.267). Ten patients with status 2 died: 6 due to acute hemodynamic compromise and 4 due to ventricular fibrillation.
\end{abstract}

Conclusions: Prognosis in status 2 patients was as poor as that of those dependent on inotrope infusion or VAD, mostly because of out-of-hospital sudden death without MCS. Status 2 patients with considerably high plasma BNP may be good candidates for continuous flow VAD therapy. (Circ $J$ 2014; 78: 1396-1404)

Key Words: Heart failure; Heart transplantation; INTERMACS

$\mathbf{S}$ urvival in patients with stage D heart failure (HF) has remained unsatisfactory in the era of guideline-directed optimal medical therapy consisting of $\beta$-blockers, angiotensin-converting enzyme inhibitors (ACEI), aldosterone antagonists, and cardiac resynchronization therapy with or without defibrillators (CRT-D). ${ }^{1}$ Although heart transplantation (HTx) is the ultimate solution for such refractory patients, approximately $90 \%$ of Japanese recipients eventually require implantation of ventricular assist device (VAD) for bridge to HTx (BTT) because of the long waiting period due to severe donor shortage. ${ }^{2}$

The current Japanese reimbursement system requires the approval of the institutional review board for the eligibility of HTx and successive HTx listings on the Japan Organ Trans- plant (JOT) Network prior to continuous flow (CF) VAD implantation. ${ }^{3}$ In Japan, extracorporeal (EC) VAD had been widely used as the only durable device until CF LVAD became available in 2011, and because of its EC nature, EC VAD was usually implanted under unstable hemodynamics. Nowadays EC VAD is still implanted in patients with cardiogenic shock as bridge to decision, and such patients may be listed for HTx after confirming eligibility later. ${ }^{4}$ Currently, EC VAD is also indicated for patients with small body surface area. HTx recipients listed on JOT Network are classified into 2 groups according to patient condition, that is, (1) 'status 1' for patients dependent on mechanical support including VAD or i.v. infusion of inotropes, equivalent to INTERMACS profile 1-3 or the United Network for Organ Sharing (UNOS)

Received January 20, 2014; revised manuscript received February 22, 2014; accepted February 26, 2014; released online April 3, 2014 Time for primary review: 28 days

Department of Cardiovascular Medicine (T. Imamura, M.H., T.F., T. Inaba, H.M., E.A., A.Y., I.K.), Department of Therapeutic Strategy for Heart Failure (K.K., S.K.), and Department of Thoracic Surgery (O.K., K.N., M.O.), Graduate School of Medicine, University of Tokyo, Tokyo, Japan

Mailing address: Koichiro Kinugawa, MD, PhD, Department of Therapeutic Strategy for Heart Failure, Graduate School of Medicine, University of Tokyo, 7-3-1 Hongo, Bunkyo-ku, Tokyo 113-8655, Japan. E-mail: kinugawa-tky@umin.ac.jp

ISSN-1346-9843 doi:10.1253/circj.CJ-14-0077

All rights are reserved to the Japanese Circulation Society. For permissions, please e-mail: cj@j-circ.or.jp 


\begin{tabular}{|c|c|c|c|c|c|c|}
\hline & $\begin{array}{c}\text { Total } \\
(n=183)\end{array}$ & $\begin{array}{c}\text { Status } 2 \\
(n=38)\end{array}$ & $\begin{array}{c}\text { Status } 1 \text { VAD } \\
(-)(n=54)\end{array}$ & $\begin{array}{l}\text { P-value vs. } \\
\text { Status } 2\end{array}$ & $\begin{array}{l}\text { Status 1 VAD } \\
(+)(n=91)\end{array}$ & $\begin{array}{c}\text { P-value vs. } \\
\text { Status } 2\end{array}$ \\
\hline \multicolumn{7}{|l|}{ Demographic parameters } \\
\hline Age (years) & $40.0 \pm 14.4$ & $38.8 \pm 17.7$ & $40.7 \pm 14.1$ & 0.728 & $40.1 \pm 13.3$ & 0.895 \\
\hline Male & $135(74.2)$ & $26(68.4)$ & $46(85.2)$ & 0.075 & $63(69.2)$ & 0.075 \\
\hline Body surface area $\left(\mathrm{m}^{2}\right)$ & $1.56 \pm 0.27$ & $1.53 \pm 0.38$ & $1.58 \pm 0.25$ & 0.132 & $1.57 \pm 0.22$ & 0.098 \\
\hline Etiology of ischemia & $27(14.8)$ & $4(10.5)$ & $5(9.3)$ & 0.412 & $18(19.8)$ & $0.024^{\dagger}$ \\
\hline $\mathrm{SBP}(\mathrm{mmHg})$ & $90.5 \pm 11.1$ & $87.6 \pm 9.7$ & $86.0 \pm 8.2$ & 0.760 & $94.4 \pm 11.8$ & $0.003^{*}$ \\
\hline Heart rate (beats/min) & $83.4 \pm 14.8$ & $82.7 \pm 14.5$ & $84.2 \pm 17.1$ & 0.885 & $83.1 \pm 13.6$ & 0.990 \\
\hline History of NSVT & $65(35.7)$ & $13(34.2)$ & $27(50.0)$ & $0.026^{\dagger}$ & $25(27.4)$ & 0.423 \\
\hline \multicolumn{7}{|l|}{ Etiology } \\
\hline DCM & $114(62.3)$ & $22(57.9)$ & 39 (72.2) & - & $53(58.2)$ & - \\
\hline ICM & $29(15.8)$ & $4(10.6)$ & $5(9.3)$ & - & $20(22.0)$ & - \\
\hline $\mathrm{ACHD}$ & $3(1.6)$ & $2(5.3)$ & $0(0)$ & - & $1(1.1)$ & - \\
\hline $\mathrm{dHCM}$ & $14(7.7)$ & $4(10.6)$ & $6(11.4)$ & - & $4(4.4)$ & - \\
\hline Secondary cardiomyopathy & $5(2.7)$ & $2(5.3)$ & $1(1.9)$ & - & $2(2.2)$ & - \\
\hline Cardiac sarcoidosis & $3(1.6)$ & $2(5.3)$ & $1(1.9)$ & - & $0(0)$ & - \\
\hline $\mathrm{RCM}$ & $3(1.6)$ & $2(5.3)$ & $0(0)$ & - & $1(1.1)$ & - \\
\hline Myocarditis & $12(6.6)$ & $0(0)$ & $2(3.8)$ & - & $10(11.0)$ & - \\
\hline \multicolumn{7}{|l|}{ Concomitant treatment } \\
\hline Furosemide (mg daily) & $39.1 \pm 33.7$ & $47.4 \pm 32.0$ & $59.6 \pm 36.7$ & 0.128 & $23.3 \pm 23.3$ & $<0.001^{*}$ \\
\hline Furosemide & $150(82.0)$ & $37(97.4)$ & $52(96.3)$ & 0.945 & $61(67.0)$ & $<0.001^{\dagger}$ \\
\hline Aldosterone antagonist (mg daily) & $33.3 \pm 21.7$ & $37.2 \pm 23.3$ & $31.3 \pm 20.9$ & 0.405 & $32.9 \pm 21.6$ & 0.571 \\
\hline Aldosterone antagonist & $157(85.8)$ & $36(94.7)$ & $46(85.2)$ & 0.734 & $75(82.4)$ & 0.834 \\
\hline$\beta$-blocker (mg daily) & $11.9 \pm 11.8$ & $10.7 \pm 7.1$ & $7.4 \pm 5.8$ & 0.354 & $15.1 \pm 14.8$ & 0.111 \\
\hline$\beta$-blocker & $172(94.0)$ & $36(94.7)$ & $51(94.4)$ & 0.998 & $85(93.4)$ & 0.984 \\
\hline ACEI/ARB (mg daily) & $3.0 \pm 2.8$ & $3.5 \pm 3.1$ & $3.4 \pm 3.0$ & 0.986 & $2.6 \pm 2.6$ & 0.231 \\
\hline ACEI/ARB & $153(83.6)$ & $35(92.1)$ & $50(92.6)$ & 0.945 & $68(74.7)$ & 0.142 \\
\hline CRT-D & 77 (42.3) & $22(57.9)$ & $34(63.0)$ & 0.634 & $21(23.1)$ & $<0.001^{\dagger}$ \\
\hline \multicolumn{7}{|l|}{ Laboratory parameters } \\
\hline White blood cells $\left(\times 10^{3} / \mu \mathrm{l}\right)$ & $6.3 \pm 1.7$ & $5.9 \pm 1.5$ & $6.3 \pm 1.5$ & 0.564 & $6.4 \pm 1.9$ & 0.280 \\
\hline Hemoglobin $(g / d l)$ & $11.8 \pm 2.0$ & $12.9 \pm 1.9$ & $12.3 \pm 2.1$ & 0.281 & $11.0 \pm 1.6$ & $<0.001^{*}$ \\
\hline Platelets $\left(\times 10^{3} / \mu \mathrm{l}\right)$ & $22.4 \pm 9.1$ & $21.5 \pm 7.1$ & $22.0 \pm 8.7$ & 0.954 & $23.1 \pm 10.0$ & 0.641 \\
\hline Serum sodium (mEq/L) & $136.2 \pm 4.5$ & $136.0 \pm 5.3$ & $134.4 \pm 4.1$ & 0.187 & $137.4 \pm 4.0$ & 0.209 \\
\hline Serum potassium (mEq/L) & $4.2 \pm 0.4$ & $4.2 \pm 0.4$ & $4.3 \pm 0.4$ & 0.837 & $4.2 \pm 0.3$ & 1.000 \\
\hline Serum BUN (mg/dl) & $23.1 \pm 4.3$ & $23.1 \pm 4.3$ & $25.1 \pm 5.8$ & 0.096 & $22.2 \pm 4.0$ & $0.001^{*}$ \\
\hline Serum creatinine $(\mathrm{mg} / \mathrm{dl})$ & $0.9 \pm 0.4$ & $0.9 \pm 0.4$ & $1.0 \pm 0.4$ & 0.275 & $0.8 \pm 0.3$ & 0.060 \\
\hline Serum albumin (g/dl) & $3.8 \pm 0.5$ & $4.0 \pm 0.6$ & $3.8 \pm 0.5$ & 0.150 & $3.6 \pm 0.5$ & $<0.001^{*}$ \\
\hline Serum GOT (IU/L) & $28.7 \pm 12.6$ & $29.1 \pm 12.3$ & $27.1 \pm 12.3$ & 0.727 & $29.4 \pm 12.9$ & 0.990 \\
\hline Serum GPT (IU/L) & $26.3 \pm 17.2$ & $27.3 \pm 18.1$ & $27.1 \pm 18.1$ & 0.964 & $24.8 \pm 15.1$ & 0.746 \\
\hline Serum LDH (IU/L) & $335.8 \pm 186.3$ & $260.9 \pm 165.1$ & $252.0 \pm 83.2$ & 0.966 & $417.6 \pm 204.2$ & $<0.001^{*}$ \\
\hline Serum total bilirubin (mg/dl) & $1.1 \pm 0.8$ & $1.1 \pm 0.6$ & $1.3 \pm 0.7$ & 0.464 & $1.1 \pm 0.9$ & 0.985 \\
\hline Plasma BNP (log $\left.{ }_{10} \mathrm{pg} / \mathrm{ml}\right)$ & $2.83 \pm 3.03$ & $2.90 \pm 2.81$ & $3.04 \pm 3.20$ & 0.353 & $2.58 \pm 2.77$ & 0.099 \\
\hline \multicolumn{7}{|l|}{ Echocardiographic parameters } \\
\hline LV diastolic diameter $(\mathrm{mm})$ & $62.2 \pm 17.0$ & $65.3 \pm 15.5$ & $71.4 \pm 15.5$ & 0.164 & $55.5 \pm 16.7$ & $0.003^{*}$ \\
\hline LV systolic diameter (mm) & $55.3 \pm 16.8$ & $57.6 \pm 15.9$ & $64.5 \pm 16.7$ & 0.087 & $48.8 \pm 16.1$ & $0.011^{*}$ \\
\hline IVSD (mm) & $7.8 \pm 1.7$ & $7.6 \pm 1.7$ & $7.8 \pm 1.9$ & 0.933 & $7.9 \pm 1.5$ & 0.610 \\
\hline PWD (mm) & $8.0 \pm 1.7$ & $7.9 \pm 1.7$ & $7.9 \pm 1.9$ & 0.989 & $8.2 \pm 1.5$ & 0.684 \\
\hline LVMI $\left(\mathrm{g} / \mathrm{m}^{2}\right)$ & $150.5 \pm 77.8$ & $171.6 \pm 68.6$ & $177.2 \pm 71.0$ & 0.932 & $126.7 \pm 76.1$ & $<0.001^{*}$ \\
\hline Ejection fraction (\%) & $23.7 \pm 11.0$ & $24.7 \pm 13.9$ & $21.1 \pm 8.7$ & 0.058 & $25.0 \pm 10.4$ & 0.970 \\
\hline AR (grade) & $0.2 \pm 0.4$ & $0.2 \pm 0.6$ & $0.2 \pm 0.4$ & 0.977 & $0.2 \pm 0.4$ & 0.998 \\
\hline MR (grade) & $1.2 \pm 0.9$ & $1.3 \pm 0.7$ & $1.6 \pm 0.9$ & 0.257 & $0.8 \pm 1.0$ & $0.003^{*}$ \\
\hline TR (grade) & $1.1 \pm 0.7$ & $1.1 \pm 0.6$ & $1.3 \pm 0.7$ & 0.491 & $1.0 \pm 0.7$ & 0.678 \\
\hline \multicolumn{7}{|l|}{ Hemodynamic parameters } \\
\hline mRAP $(\mathrm{mmHg})$ & $8.1 \pm 4.4$ & $6.9 \pm 8.6$ & $6.3 \pm 4.3$ & 0.321 & $8.4 \pm 4.6$ & 0.218 \\
\hline mPAP $(\mathrm{mmHg})$ & $23.8 \pm 8.9$ & $24.9 \pm 8.6$ & $28.0 \pm 10.5$ & 0.068 & $21.7 \pm 6.3$ & 0.108 \\
\hline PCWP (mmHg) & $16.8 \pm 8.1$ & $18.4 \pm 7.9$ & $21.9 \pm 8.6$ & 0.070 & $13.2 \pm 5.8$ & $0.001^{*}$ \\
\hline $\mathrm{Cl}\left(\mathrm{L} \cdot \mathrm{min}^{-1} \cdot \mathrm{m}^{-2}\right)$ & $2.3 \pm 0.7$ & $2.2 \pm 0.5$ & $2.0 \pm 0.4$ & 0.427 & $2.5 \pm 0.7$ & $0.025^{\star}$ \\
\hline PVR (WU) & $2.2 \pm 1.2$ & $2.1 \pm 1.4$ & $2.5 \pm 1.1$ & 0.169 & $2.1 \pm 1.1$ & 0.987 \\
\hline $\operatorname{RVSWI}\left(\mathrm{g} / \mathrm{m}^{2}\right)$ & $6.2 \pm 3.2$ & $6.4 \pm 2.6$ & $7.3 \pm 3.6$ & 0.374 & $5.4 \pm 3.0$ & 0.250 \\
\hline CVP/PCWP & $0.5 \pm 0.3$ & $0.4 \pm 0.2$ & $0.4 \pm 0.2$ & 0.971 & $0.7 \pm 0.4$ & $<0.001^{*}$ \\
\hline
\end{tabular}


Data given as mean $\pm \mathrm{SD}$ or $\mathrm{n}(\%) .{ }^{*} \mathrm{P}<0.05$ (unpaired t-test or Mann-Whitney test as appropriate); ${ }^{\mathrm{P}} \mathrm{P}<0.05$ (Chi-squared test or Fisher's exact test as appropriate).

$\mathrm{ACEl}$, angiotensin-converting enzyme inhibitor; $\mathrm{ACHD}$, adult congenital heart disease; $\mathrm{AR}$, aortic regurgitation; ARB angiotensin receptor blocker; BNP, B-type natriuretic peptide; BUN, blood urea nitrogen; Cl, cardiac index; CRT-D, cardiac resynchronization therapy with defibrillator; CVP, central venous pressure; DCM, dilated cardiomyopathy; dHCM, dilated phase of hypertrophic cardiomyopathy; GOT, glutamic oxaloacetic transaminase; GPT, glutamic pyruvic transaminase; ICM, ischemic cardiomyopathy; IVSD, interventricular septum diameter; LDH, lactate dehydrogenase; LV left ventricle; LVMI, left ventricular mass index; mPAP, mean pulmonary artery pressure; MR, mitral regurgitation; mRAP, mean right atrial pressure; NSVT, non-sustained ventricular tachycardia; PCWP, pulmonary capillary wedge pressure; PVR, pulmonary vascular resistance; PWD, posterior wall diameter; RCM, restrictive cardiomyopathy; RVSWI, right ventricular stroke work index; SBP, systolic blood pressure; TR, tricuspid regurgitation; VAD, ventricular assist device.

\section{A. Status $2(\mathrm{~N}=38)$}

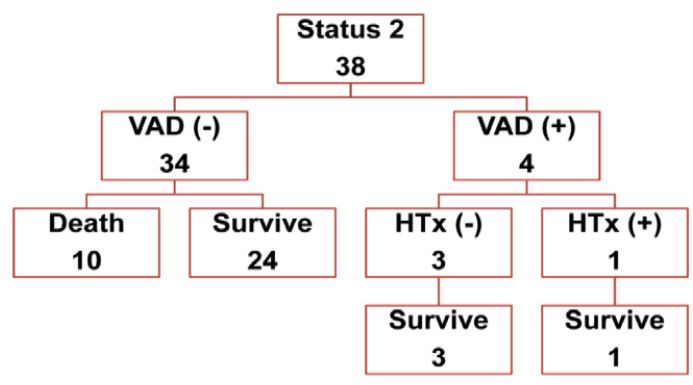

B. Status 1 VAD (-) ( $N=54)$

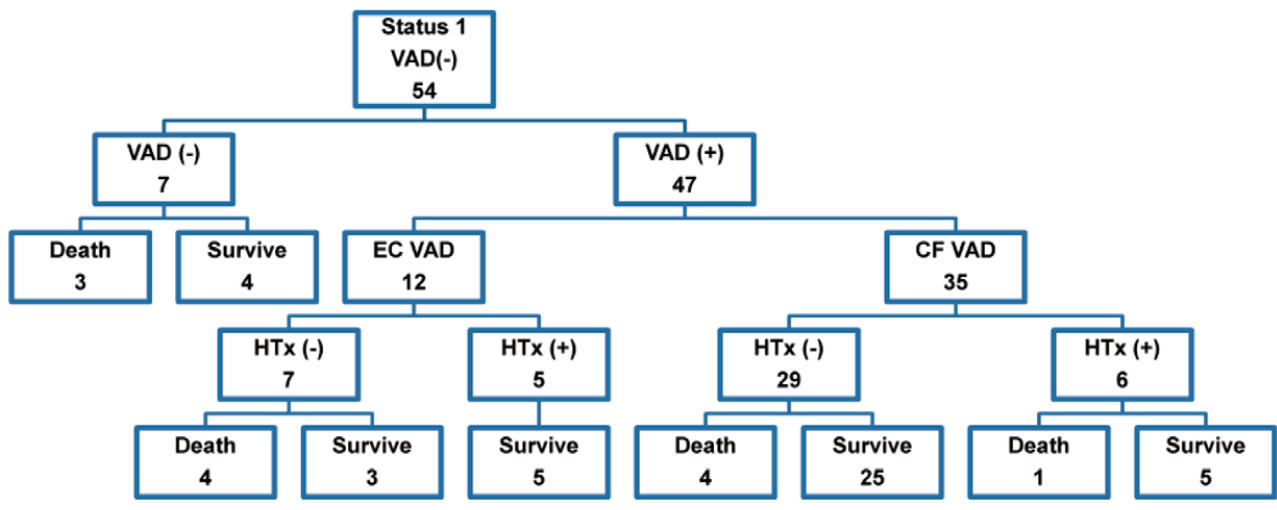

\section{Status 1 VAD $(+)(\mathrm{N}=91)$}

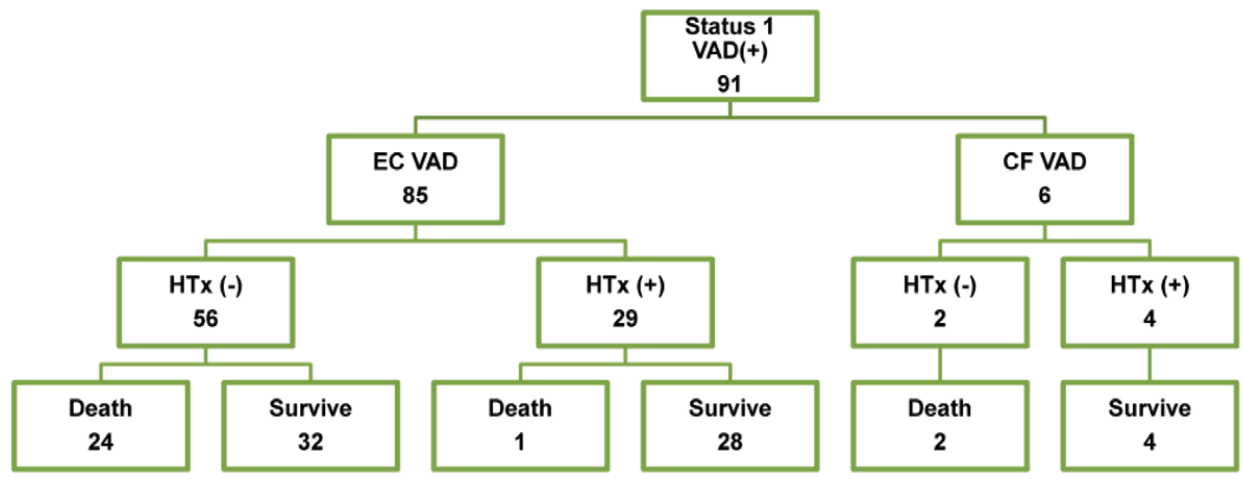

Figure 1. Time course after review board approval for heart transplantation ( $\mathrm{HTx}$ ) listing in patients with (A) status 2; (B) status 1 without ventricular assist device (VAD); and (C) status 1 with VAD. CF, continuous flow; EC, extracorporeal. 
A

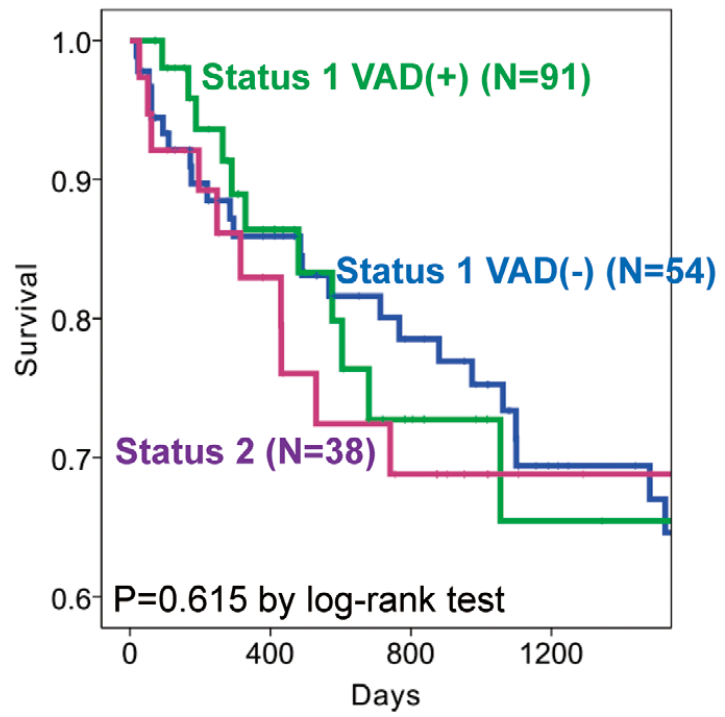

B

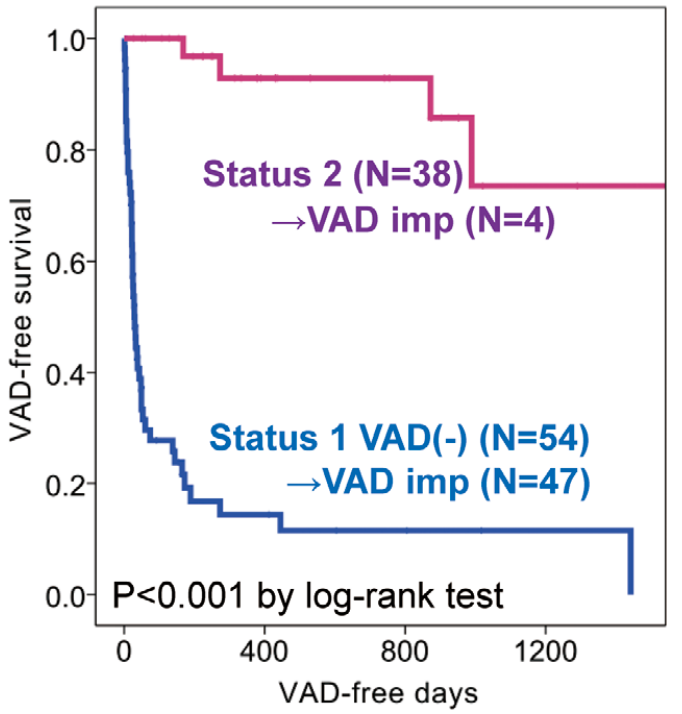

Figure 2. (A) Four-year survival among the 3 groups; and (B) ventricular assist device (VAD)-free survival in status 2 patients and in status 1 without VAD over 4 years. imp, implantation.

status code 1A and 1B; or (2) "status 2" for patients with New York Heart Association (NYHA) IV symptom but free from continuous inotrope infusion or mechanical circulatory support (MCS), equivalent to INTERMACS profile 4-6 or UNOS status code status $2 . .^{5-7}$

Considering its cost, adverse events, and quality of life during VAD treatment, ${ }^{8}$ all listed patients are not necessarily considered as candidates for VAD therapy. Thus far, MCS as a tool for BTT has been indicated mostly for patients with status 1 , and a number of authors including us have reported preoperative survival risk factors for optimal selection among them. ${ }^{3,9-16}$ The indication for MCS in patients with status 2, however, has not been well described. Patients with status 2 are basically outpatients, and it may be difficult for health-care providers to respond to acute hemodynamic deterioration. On the one hand, many people consider that MCS indication is too early for status 2 patients, but, on the other hand, we should not be too late. Therefore, we compared patient prognosis between status 1 and 2 with or without MCS, and identified a therapeutic borderline between medical and MCS therapy in status 2 patients.

\section{Methods}

\section{Patient Selection}

We retrospectively analyzed 183 consecutive patients with stage D HF who were evaluated by the review board for HTx listing in the University of Tokyo Hospital and then listed for HTx on JOT Network between January 2003 and August 2013. All patients had been treated with guideline-directed medical therapy consisting of $\beta$-blockers, ACEI or angiotensin II receptor blockers (ARB), and aldosterone antagonists unless contraindicated. CRT-D was introduced if indicated. Before evaluation by the board, all patients received full examination to confirm eligibility for HTx. ${ }^{6}$ In patients assigned to status 2 , peak oxygen consumption (peak $\dot{V O}_{2}$ ) $\leq 14 \mathrm{ml} \cdot \mathrm{kg}^{-1} \cdot \mathrm{min}^{-1}$ on cardiopulmonary exercise test was an indispensable eligibility for HTx listing.

EC VAD was implanted as BTT or bridge to decision in patients with acute decline of hemodynamics with or without the approval of the review board. A small number of CF VAD was also implanted in patients under the clinical trials before review board approval for HTx. After confirming eligibility for HTx, they were listed as status 1 .

Written informed consent was obtained at admission from the patients and/or their family members in all cases. The study protocol was approved by the Ethics Committee of Graduate School of Medicine, University of Tokyo (application number 779 [1]).

\section{Variables Evaluated}

Patients were enrolled at the time of approval by the institutional review board for HTx. All patients enrolled were listed on JOT Network later. Patient demographic, laboratory, echocardiographic, and hemodynamic parameters obtained $<1$ month before review board approval were analyzed in this study. In patients with VAD, postoperative data were used. History of non-sustained ventricular tachycardia (NSVT) was confirmed on 24-h Holter electrocardiogram. To evaluate effects of different types of $\beta$-blocker, the dose of bisoprolol was normalized to the approximately equivalent dose of carvedilol according to efficacy. For example, we regarded $5 \mathrm{mg}$ of bisoprolol as $20 \mathrm{mg}$ of carvedilol. ${ }^{17}$ In the same manner, the doses of ACEI/ARB were normalized to the approximately equivalent dose of enalapril. For example, $4 \mathrm{mg}$ of candesartan was regarded as $5 \mathrm{mg}$ of enalapril. ${ }^{18}$

\section{Statistical Analysis}

All statistical analysis was done using PASW Statistics 18 (SPSS, Chicago, IL, USA) or JMP9 (SAS Institute, Cary, NC, USA). Categorical variables were summarized as frequencies and percentages, and compared using Chi-squared test or 


\begin{tabular}{|c|c|c|c|c|c|}
\hline & $\begin{array}{l}\text { Death } \\
(n=22)\end{array}$ & $\begin{array}{c}\text { Survival } \\
(n=70)\end{array}$ & P-value & $\begin{array}{l}\text { Hazard } \\
\text { ratio }\end{array}$ & $\begin{array}{l}95 \% \text { confidence } \\
\text { interval }\end{array}$ \\
\hline \multicolumn{6}{|l|}{ Demographic parameters } \\
\hline Age (years) & $39.6 \pm 18.5$ & $40.0 \pm 14.7$ & 0.631 & 0.993 & $0.966-1.021$ \\
\hline Male & $17(77.3)$ & $55(78.6)$ & 0.952 & 1.030 & $0.384-2.763$ \\
\hline Body surface area $\left(\mathrm{m}^{2}\right)$ & $1.57 \pm 0.26$ & $1.47 \pm 0.46$ & 0.147 & 0.434 & $0.141-1.340$ \\
\hline Etiology of ischemia & $2(9.1)$ & $7(10.0)$ & 0.815 & 0.840 & $0.195-3.613$ \\
\hline Systolic blood pressure $(\mathrm{mmHg})$ & $88.2 \pm 10.5$ & $86.2 \pm 8.3$ & 0.391 & 1.018 & $0.977-1.061$ \\
\hline Heart rate (beats/min) & $83.0 \pm 14.6$ & $85.4 \pm 20.2$ & 0.681 & 1.005 & $0.980-1.031$ \\
\hline History of NSVT & $9(40.9)$ & $31(44.3)$ & 0.907 & 0.952 & $0.418-2.167$ \\
\hline \multicolumn{6}{|l|}{ Concomitant treatment } \\
\hline Furosemide (mg daily) & $62.7 \pm 46.7$ & $52.0 \pm 30.7$ & 0.508 & 1.004 & $0.993-1.015$ \\
\hline Spironolactone (mg daily) & $33.5 \pm 25.4$ & $33.8 \pm 20.1$ & 0.906 & 1.001 & $0.983-1.020$ \\
\hline$\beta$-blocker (mg daily) & $8.0 \pm 7.2$ & $9.0 \pm 6.4$ & 0.732 & 0.989 & $0.927-1.054$ \\
\hline ACEI/ARB (mg daily) & $3.7 \pm 4.7$ & $3.3 \pm 2.2$ & 0.301 & 1.066 & $0.944-1.203$ \\
\hline CRT-D & $11(50.0)$ & $45(64.3)$ & 0.397 & 0.699 & $0.305-1.602$ \\
\hline \multicolumn{6}{|l|}{ Laboratory parameters } \\
\hline White blood cells $\left(\times 10^{3} / \mu \mathrm{l}\right)$ & $6.1 \pm 1.8$ & $6.2 \pm 1.4$ & 0.639 & 0.964 & $0.934-1.074$ \\
\hline Hemoglobin (g/dl) & $12.5 \pm 2.0$ & $12.5 \pm 2.1$ & 0.287 & 1.108 & $0.917-1.338$ \\
\hline Platelets $\left(\times 10^{3} / \mu \mathrm{l}\right)$ & $23.7 \pm 10.7$ & $21.2 \pm 7.0$ & 0.336 & 1.023 & $0.977-1.071$ \\
\hline Serum sodium (mEq/L) & $134.0 \pm 6.4$ & $135.4 \pm 4.0$ & 0.694 & 0.984 & $0.906-1.068$ \\
\hline Serum potassium (mEq/L) & $4.3 \pm 0.4$ & $4.2 \pm 0.4$ & 0.394 & 1.514 & $0.583-3.935$ \\
\hline Serum BUN (mg/dl) & $25.0 \pm 7.4$ & $24.1 \pm 4.5$ & 0.406 & 1.032 & $0.958-1.112$ \\
\hline Serum creatinine (mg/dl) & $1.0 \pm 0.5$ & $1.0 \pm 0.4$ & 0.987 & 0.991 & $0.348-2.823$ \\
\hline Serum albumin (g/dl) & $3.7 \pm 0.4$ & $4.0 \pm 0.6$ & 0.124 & 0.604 & $0.318-1.148$ \\
\hline Serum GOT (IU/L) & $33.3 \pm 13.1$ & $26.2 \pm 11.6$ & 0.076 & 1.033 & $0.974-1.063$ \\
\hline Serum GPT (IU/L) & $31.0 \pm 23.1$ & $26.8 \pm 17.6$ & 0.475 & 1.008 & $0.987-1.029$ \\
\hline Serum LDH (IU/L) & $301.3 \pm 200.2$ & $255.4 \pm 77.6$ & 0.243 & 1.006 & $0.988-1.034$ \\
\hline Serum total bilirubin (mg/dl) & $1.2 \pm 0.7$ & $1.2 \pm 0.8$ & 0.821 & 1.072 & $0.587-1.959$ \\
\hline Plasma BNP (log $\left.{ }_{10} \mathrm{pg} / \mathrm{ml}\right)$ & $3.01 \pm 2.88$ & $2.98 \pm 3.18$ & 0.324 & 0.976 & $0.923-1.084$ \\
\hline \multicolumn{6}{|l|}{ Echocardiographic parameters } \\
\hline LV diastolic diameter (mm) & $67.1 \pm 19.4$ & $69.4 \pm 14.5$ & 0.749 & 0.996 & $0.971-1.022$ \\
\hline LV systolic diameter (mm) & $58.4 \pm 20.0$ & $62.7 \pm 14.7$ & 0.575 & 0.993 & $0.969-1.017$ \\
\hline IVS (mm) & $7.9 \pm 2.5$ & $7.7 \pm 1.7$ & 0.867 & 1.018 & $0.824-1.258$ \\
\hline $\mathrm{PW}(\mathrm{mm})$ & $8.1 \pm 2.1$ & $7.9 \pm 1.7$ & 0.976 & 1.003 & $0.809-1.244$ \\
\hline LVMI $\left(\mathrm{g} / \mathrm{m}^{2}\right)$ & $182.2 \pm 76.5$ & $172.5 \pm 67.8$ & 0.664 & 1.001 & $0.996-1.006$ \\
\hline Ejection fraction (\%) & $26.2 \pm 15.0$ & $21.1 \pm 9.8$ & 0.268 & 1.017 & $0.987-1.048$ \\
\hline AR (grade) & $0.2 \pm 0.7$ & $0.2 \pm 0.4$ & 0.465 & 1.354 & $0.601-3.052$ \\
\hline MR (grade) & $1.4 \pm 0.9$ & $1.5 \pm 0.8$ & 0.628 & 0.997 & $0.546-1.441$ \\
\hline TR (grade) & $1.2 \pm 0.8$ & $1.2 \pm 0.7$ & 0.945 & 1.022 & $0.552-1.893$ \\
\hline \multicolumn{6}{|l|}{ Hemodynamic parameters } \\
\hline mRAP $(\mathrm{mmHg})$ & $9.2 \pm 3.3$ & $7.4 \pm 4.4$ & 0.087 & 1.112 & $0.978-1.228$ \\
\hline mPAP $(\mathrm{mmHg})$ & $29.9 \pm 7.5$ & $27.4 \pm 10.6$ & 0.219 & 1.028 & $0.983-1.075$ \\
\hline PCWP $(\mathrm{mmHg})$ & $22.2 \pm 6.4$ & $20.0 \pm 8.9$ & 0.179 & 1.037 & $0.984-1.093$ \\
\hline $\mathrm{Cl}\left(\mathrm{L} \cdot \mathrm{min}^{-1} \cdot \mathrm{m}^{-2}\right)$ & $2.0 \pm 0.5$ & $2.1 \pm 0.5$ & 0.403 & 0.64 & $0.225-1.819$ \\
\hline PVR (WU) & $2.3 \pm 0.9$ & $2.4 \pm 1.3$ & 0.889 & 0.974 & $0.668-1.419$ \\
\hline RVSWI $\left(g / m^{2}\right)$ & $7.2 \pm 2.8$ & $6.9 \pm 3.3$ & 0.730 & 1.025 & $0.890-1.180$ \\
\hline CVP/PCWP & $0.4 \pm 0.2$ & $0.4 \pm 0.3$ & 0.272 & 3.531 & $0.371-33.58$ \\
\hline
\end{tabular}

Data given as mean \pm SD or $n(\%)$. ${ }^{*}<<0.05$ (Cox regression analysis).

Abbreviations as in Table 1.

Fisher's exact test as appropriate. Continuous variables are represented as mean $\pm \mathrm{SD}$ unless otherwise specified, and compared using unpaired t-test or Mann-Whitney test as appropriate. Variables of status 1 and 2 with/without VAD were compared using ad-hoc Tukey test when analysis of variance confirmed significance. Kaplan-Meier analysis was done with log-rank test for survival over 4 years. Cox regression analysis was used to examine significant factors for survival. Receiver operating characteristic (ROC) analysis was used to calculate a cut-off value of plasma B-type natriuretic peptide (BNP) for survival in the status 2 group. All hypothesis tests reported are 2-tailed, and $\mathrm{P}<0.05$ was set as significant. 
A $\operatorname{VAD}(-)(\mathrm{N}=92)$

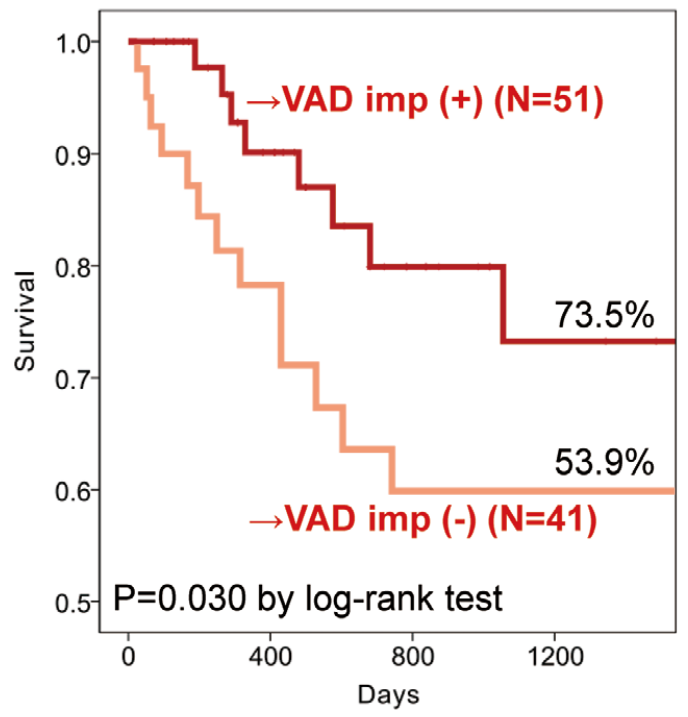

B Status $2(\mathrm{~N}=38)$

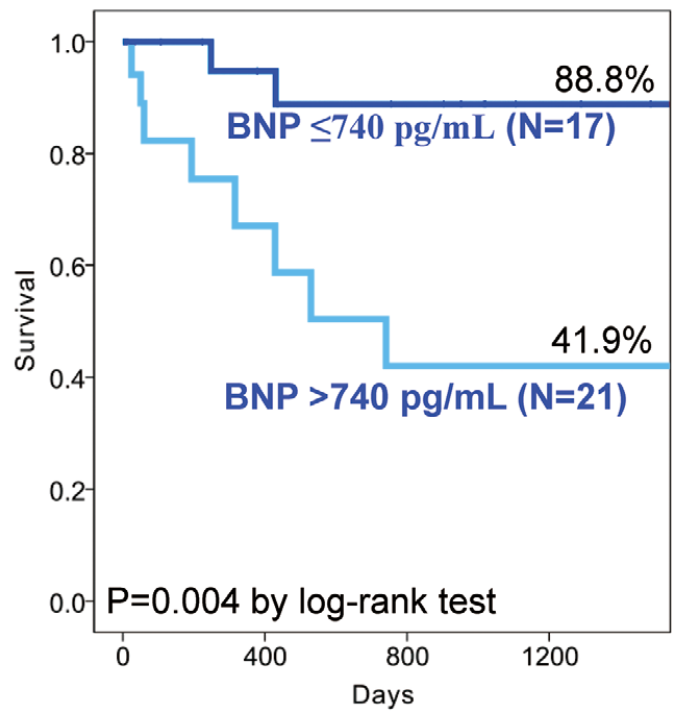

Figure 3. Four-year survival in (A) patients without ventricular assist device (VAD) stratified by eventual VAD implantation (imp); and (B) status 2 patients stratified according to plasma B-type natriuretic peptide (BNP) level.

\section{Results}

\section{Patient Baseline Characteristics}

Dilated cardiomyopathy and ischemic cardiomyopathy were the dominant etiologies of HF in all 3 groups (Table 1). Dilated phase of hypertrophic cardiomyopathy was another major etiology of HF in the status 2 and the status 1 without VAD groups. Fulminant myocarditis was the third major etiology of HF in the status 1 with VAD group.

There were no statistical differences in demographic, laboratory, echocardiographic, and hemodynamic parameters between the status 2 and the status 1 without VAD groups except for higher prevalence of previous NSVT in the latter group ( $34.2 \%$ vs. $50.0 \%, \mathrm{P}=0.026$ ). The status 1 with $\mathrm{VAD}$ group had a higher prevalence of improved hemodynamics along with unloaded left ventricle regardless of lower dose of diuretics (all $\mathrm{P}<0.05$ compared with status 2 ).

\section{Clinical Course Over 4 Years at Time of Review Board Approval} In the status 2 group $(n=38)$, only 4 patients $(10.5 \%)$ received VAD treatment eventually, and all of them survived during the study period (Figure 1A). Peak $\mathrm{VO}_{2}$ averaged $12.0 \pm 3.6 \mathrm{ml}$. $\mathrm{kg}^{-1} \cdot \mathrm{min}^{-1}$, and all patients were assigned INTERMACS profile 4-6 at the time of enrollment (profile 4, 12 patients, $31.6 \%$; profile 5, 21 patients, $55.3 \%$; profile 6,5 patients, $13.2 \%$ ). Of the patients without VAD treatment, 10 patients $(29.4 \%)$ died ( 6 due to acute hemodynamic compromise and 4 due to ventricular fibrillation [Vf]). Of the 4 patients who died due to Vf, 2 patients had received CRT-D previously.

In the status 1 without VAD group $(n=54), 47$ patients $(87.0 \%)$ received $\mathrm{VAD}$ treatment eventually $(\mathrm{CF}, 35$ patients, $74.5 \%$; EC, 12 patients, 25.5\%; Figure 1B). All patients were assigned INTERMACS profile 2 or 3 at the time of enrollment (profile 2, 23 patients, 42.6\%; profile 3, 31 patients, 57.4\%). Eleven patients $(20.3 \%)$ received HTx eventually and, of them, only 1 patient died. Five patients $(14.3 \%)$ died during CF VAD support, whereas 4 patients (33.3\%) died during EC VAD support. Cause of death was multiple organ failure or stroke after VAD implantation.

In the VAD group $(n=91), 85$ patients $(93.4 \%)$ had already received EC VAD, and 6 patients $(6.6 \%)$ had CF VAD under the clinical trials (Figure 1C). All patients were assigned INTERMACS profile 1 or 2 before VAD implantation (profile 1, 50 patients, $54.9 \%$; profile 2,41 patients, $45.1 \%$ ). Thirtythree patients $(36.3 \%)$ received HTx eventually and, of them, only 1 patient died. While waiting for HTx, 26 patients (44.8\%) died under VAD treatment.

There were no significant differences in overall survival among the 3 groups over 4 years (status 2, 68.8\%; status 1 without VAD, 65.5\%; and status 1 with $\mathrm{VAD}, 64.6 \%, \mathrm{P}=0.615$; Figure 2A). Patients assigned status 1 without VAD had markedly lower VAD-free survival than those of status 2 over 4 years $(11.5 \%$ vs. $73.5 \%, \mathrm{P}<0.001$; Figure $2 \mathrm{~B})$.

\section{Risk Analysis for Survival in Patients Without VAD at Time of Review Board Approval}

On Cox regression analysis there were no significant predictors for 4-year survival in patients without VAD treatment (including both status 1 and 2) at the time of review board approval $(n=92$; Table 2), whereas more than half of the patients $(n=51$, $55 \%$ ) eventually received VAD therapy as shown in Figure 2B, and clinical course was affected by MCS. Consistently, eventual VAD implantation significantly stratified 4-year survival in patients without VAD treatment according to Kaplan-Meier analysis $(\mathrm{P}=0.030$, log-rank test; Figure $\mathbf{3 A})$.

In contrast, Cox regression analysis showed that higher plasma BNP was the only significant predictor of 4-year mortality in status 2 patients $(\mathrm{P}=0.024$, hazard ratio [HR], 8.267; Table 3). On ROC analysis the cut-off level of plasma BNP was $740 \mathrm{pg} / \mathrm{ml}$ (area under the curve, 0.704; sensitivity, 0.800; 
Table 3. Predictors of Survival in Status 2 Patients at the Time of Review Board Approval

\begin{tabular}{|c|c|c|c|c|c|}
\hline Total $n=38$ & $\begin{array}{l}\text { Death } \\
(n=10)\end{array}$ & $\begin{array}{l}\text { Survive } \\
(n=28)\end{array}$ & P-value & $\begin{array}{c}\text { Hazard } \\
\text { ratio }\end{array}$ & $\begin{array}{l}95 \% \text { confidence } \\
\text { interval }\end{array}$ \\
\hline \multicolumn{6}{|l|}{ Demographic parameters } \\
\hline Age (years) & $32.9 \pm 17.1$ & $41.0 \pm 17.6$ & 0.163 & 0.977 & $0.945-1.010$ \\
\hline Male & $6(60.0)$ & $20(71.4)$ & 0.363 & 0.556 & $0.156-1.973$ \\
\hline Body surface area $\left(\mathrm{m}^{2}\right)$ & $1.31 \pm 0.51$ & $1.48 \pm 0.32$ & 0.217 & 0.420 & $0.106-1.662$ \\
\hline Etiology of ischemia & $0(0)$ & $4(14.3)$ & 0.495 & 0.042 & $0.001-372.6$ \\
\hline Systolic blood pressure (mmHg) & $86.2 \pm 12.0$ & $88.1 \pm 9.0$ & 0.596 & 0.983 & $0.921-1.048$ \\
\hline Heart rate (beats/min) & $90.0 \pm 16.8$ & $80.1 \pm 13.0$ & 0.068 & 1.043 & $0.998-1.090$ \\
\hline History of NSVT & $5(50.0)$ & $9(32.1)$ & 0.972 & 1.022 & $0.297-3.515$ \\
\hline Peak VOO $2\left(\mathrm{ml} \cdot \mathrm{kg}^{-1} \cdot \mathrm{min}^{-1}\right)$ & $10.9 \pm 3.3$ & $11.9 \pm 3.8$ & 0.708 & 1.033 & $0.873-1.221$ \\
\hline \multicolumn{6}{|l|}{ Concomitant treatment } \\
\hline Furosemide (mg daily) & $46.0 \pm 40.9$ & $47.9 \pm 29.1$ & 0.718 & 0.996 & $0.975-1.018$ \\
\hline Spironolactone (mg daily) & $37.5 \pm 27.0$ & $37.1 \pm 22.4$ & 0.850 & 1.002 & $0.977-1.028$ \\
\hline$\beta$-blocker (mg daily) & $9.1 \pm 8.2$ & $11.3 \pm 6.7$ & 0.451 & 0.962 & $0.870-1.064$ \\
\hline ACEI/ARB (mg daily) & $3.1 \pm 4.3$ & $3.6 \pm 2.6$ & 0.802 & 1.032 & $0.806-1.322$ \\
\hline CRT-D & $4(40.0)$ & $18(64.3)$ & 0.181 & 0.420 & $0.118-1.496$ \\
\hline \multicolumn{6}{|l|}{ Laboratory parameters } \\
\hline White blood cells $\left(\times 10^{3} / \mu \mathrm{l}\right)$ & $5.4 \pm 1.4$ & $6.1 \pm 1.5$ & 0.087 & 0.596 & $0.37-1.023$ \\
\hline Hemoglobin (g/dl) & $13.3 \pm 1.6$ & $12.8 \pm 2.0$ & 0.273 & 1.203 & $0.865-1.672$ \\
\hline Platelets $\left(\times 10^{3} / \mu \mathrm{l}\right)$ & $19.3 \pm 5.0$ & $22.2 \pm 7.6$ & 0.361 & 0.951 & $0.854-1.059$ \\
\hline Serum sodium (mEq/L) & $135.4 \pm 8.0$ & $136.2 \pm 4.1$ & 0.868 & 1.010 & $0.902-1.130$ \\
\hline Serum potassium (mEq/L) & $4.2 \pm 0.4$ & $4.2 \pm 0.3$ & 0.573 & 0.652 & $0.147-2.885$ \\
\hline Serum BUN (mg/dl) & $22.5 \pm 6.3$ & $23.3 \pm 3.4$ & 0.672 & 0.972 & $0.851-1.109$ \\
\hline Serum creatinine (mg/dl) & $0.9 \pm 0.4$ & $0.9 \pm 0.5$ & 0.432 & 0.521 & $0.102-2.653$ \\
\hline Serum albumin (g/dl) & $3.8 \pm 0.5$ & $4.1 \pm 0.6$ & 0.355 & 0.669 & $0.285-1.568$ \\
\hline Serum GOT (IU/L) & $33.3 \pm 14.6$ & $27.6 \pm 11.3$ & 0.151 & 1.031 & $0.989-1.076$ \\
\hline Serum GPT (IU/L) & $28.6 \pm 18.9$ & $26.8 \pm 18.1$ & 0.664 & 1.008 & $0.974-1.042$ \\
\hline Serum LDH (IU/L) & $336.4 \pm 282.5$ & $269.6 \pm 63.8$ & 0.223 & 1.005 & $0.997-1.014$ \\
\hline Serum total bilirubin (mg/dl) & $1.2 \pm 0.7$ & $1.0 \pm 0.6$ & 0.504 & 1.391 & $0.529-3.62$ \\
\hline Plasma BNP (log $\left.{ }_{10} \mathrm{pg} / \mathrm{ml}\right)$ & $2.96 \pm 0.35$ & $2.70 \pm 0.34$ & $0.024^{*}$ & 8.267 & $1.041-65.66$ \\
\hline Plasma BNP >740 pg/ml & $8(80.0)$ & $9(32.1)$ & $0.014^{*}$ & 7.037 & $1.487-33.29$ \\
\hline \multicolumn{6}{|l|}{ Echocardiographic parameters } \\
\hline LV diastolic diameter (mm) & $64.6 \pm 21.4$ & $65.6 \pm 13.3$ & 0.829 & 0.995 & $0.954-1.038$ \\
\hline LV systolic diameter (mm) & $54.7 \pm 21.3$ & $58.6 \pm 13.8$ & 0.545 & 0.988 & $0.952-1.026$ \\
\hline IVS (mm) & $7.4 \pm 2.5$ & $7.7 \pm 1.6$ & 0.636 & 0.916 & $0.636-1.318$ \\
\hline $\mathrm{PW}(\mathrm{mm})$ & $7.8 \pm 2.5$ & $7.9 \pm 1.3$ & 0.800 & 0.947 & $0.621-1.444$ \\
\hline LVMI (g/m²) & $177.1 \pm 82.9$ & $169.6 \pm 64.3$ & 0.813 & 1.001 & $0.992-1.010$ \\
\hline Ejection fraction (\%) & $30.8 \pm 18.3$ & $23.6 \pm 11.8$ & 0.314 & 1.018 & $0.983-1.055$ \\
\hline AR (grade) & $0.3 \pm 0.9$ & $0.1 \pm 0.4$ & 0.394 & 1.461 & $0.611-3.497$ \\
\hline MR (grade) & $1.5 \pm 0.9$ & $1.3 \pm 0.6$ & 0.253 & 1.774 & $0.665-4.734$ \\
\hline TR (grade) & $1.1 \pm 0.9$ & $1.1 \pm 0.6$ & 0.681 & 0.824 & $0.328-2.072$ \\
\hline \multicolumn{6}{|l|}{ Hemodynamic parameters } \\
\hline mRAP $(\mathrm{mmHg})$ & $7.8 \pm 3.8$ & $6.7 \pm 4.2$ & 0.513 & 1.051 & $0.905-1.221$ \\
\hline mPAP $(\mathrm{mmHg})$ & $27.8 \pm 8.7$ & $24.1 \pm 8.6$ & 0.263 & 1.043 & $0.969-1.123$ \\
\hline PCWP (mmHg) & $21.0 \pm 6.1$ & $17.7 \pm 8.3$ & 0.331 & 1.039 & $0.961-1.124$ \\
\hline $\mathrm{Cl}\left(\mathrm{L} \cdot \mathrm{min}^{-1} \cdot \mathrm{m}^{-2}\right)$ & $2.2 \pm 0.6$ & $2.2 \pm 0.5$ & 0.991 & 0.993 & $0.304-3.246$ \\
\hline PVR (WU) & $1.8 \pm 0.8$ & $2.2 \pm 1.4$ & 0.918 & 0.974 & $0.594-1.597$ \\
\hline RVSWI $\left(g / m^{2}\right)$ & $6.7 \pm 2.7$ & $6.3 \pm 2.6$ & 0.574 & 1.069 & $0.848-1.347$ \\
\hline CVP/PCWP & $0.4 \pm 0.2$ & $0.4 \pm 0.2$ & 0.892 & 0.786 & $0.024-25.88$ \\
\hline
\end{tabular}

Data given as mean $\pm \mathrm{SD}$ or $\mathrm{n}(\%) .{ }^{*} \mathrm{P}<0.05$ (Cox regression analysis).

Abbreviations as in Table 1.

specificity, 0.607), and plasma BNP concentration $>740 \mathrm{pg} / \mathrm{ml}$ had HR 7.037 on Cox regression analysis $(\mathrm{P}=0.014)$. KaplanMeier analysis significantly stratified 4-year survival in patients with status 2 according to plasma BNP level $(\mathrm{P}=0.004$, log-rank test; Figure 3B).

\section{Discussion}

Among 183 consecutive patients with stage D HF who were evaluated by the review board of the University of Tokyo Hospital for HTx listing, the prognosis of status 2 patients was 
as poor as those of status 1 with or without VAD treatment over 4 years. Eventual VAD implantation provided significantly better 4-year survival in patients without VAD treatment regardless of any baseline characteristics. On Cox regression analysis plasma BNP $>740 \mathrm{pg} / \mathrm{ml}$ was the only significant predictor for 4-year mortality among status 2 patients.

\section{Patient Prognosis}

The VAD group had the sickest preoperative background because a large proportion of them had had INTERMACS profile 1 , and received MCS due to cardiogenic shock. The group of status 1 without VAD, which was equivalent to INTERMACS profile 2 or 3 , also had a sicker background, because i.v. inotropes could not be discontinued due to refractory HF. Surprisingly, less sick patients with status 2, equivalent to INTERMCS profile 4-6, had a prognosis as poor as other 2 groups. Nader et al consistently reported that UNOS status 2 patients, equivalent to those with JOT status 2, had a poor prognosis without transplantation (3-year survival with/without HTx, 87\% vs. $57 \%, \mathrm{P}<0.01) .{ }^{19}$ Patient baseline characteristics including endorgan function and plasma BNP level of the status 1 group were as good as those of status 2 at the time of review board approval. Accordingly, not only MCS but intensive inotropic support could successfully maintain hemodynamics for a certain period. Approximately $90 \%$ of inotrope-dependent patients, however, needed VAD therapy within 1 year (cf. Figure 2B), and we should remember that inotropes are not as powerful as MCS for support on a month-to-month basis.

\section{VAD Indication in Status 1 and 2}

Previously established predictors of survival in HF patients, such as hyponatremia, chronic kidney disease, and high plasma BNP, 20-22 were not risk factors for survival among patients without VAD. Instead, VAD implantation provided significantly better survival. Among patients who are destined to receive MCS, such biomarkers may not simply become good predictors for survival. Consistent with this, Kelsey et al recently reported that previously developed preoperative health status had a limited association with outcome in patients who received HeartMate II VAD. ${ }^{23}$

CF VAD is indicated in patients with status 1, whereas those with status 2 have rarely received VAD treatment thus far in Japan., 10,24 INTERMACS similarly reported that not many (18.3\%) of less sick patients (ie, profile 4-7) received VAD treatment in the past. ${ }^{8}$ Among the status 2 group, 4 patients $(10.5 \%)$ eventually received VAD treatment via status 1 due to worsening of $\mathrm{HF}$, and all patients remained alive. The other 34 patients $(89.5 \%)$ did not receive VAD implantation simply because they were assigned the less sick status 2 . Boyle et al found that patients assigned INTERMACS profile 4-7, that is, almost equivalent to status 2 in Japan, had better 3-year survival after CF VAD implantation than the group who was more acutely ill. ${ }^{25}$ Then, the next question is whether all patients with status 2 should receive VAD implantation.

\section{Selection for VAD in Status 2}

Plasma BNP $>740 \mathrm{pg} / \mathrm{ml}$ was the only significant risk factor for mortality in the status 2 group, and 20 patients (52.6\%) had plasma BNP $>740 \mathrm{pg} / \mathrm{ml}$. In other words, approximately half of the status 2 patients had been followed as outpatients without MCS, albeit with considerably high plasma BNP. Consistent with this, Kato et al reported that patients with peak $\dot{\mathrm{VO}} 210-14 \mathrm{ml} \cdot \mathrm{min}^{-1} \cdot \mathrm{kg}^{-1}$ had a worse prognosis when they had plasma BNP $\geq 506 \mathrm{pg} / \mathrm{ml}^{26}$ All 10 deceased patients died due to acute deterioration of hemodynamics or fatal ventricu- lar tachyarrhythmia. Their plasma BNP was already high $(1197 \pm 943 \mathrm{pg} / \mathrm{ml}$ at the time of review board approval. Status 2 patients with higher plasma BNP appear to have high risk for sudden death, and may be good candidates for MCS in terms of survival benefit. Moreover, most of the deceased patients were followed in other hospitals, where VAD treatment could not be carried out. It might be better for such high-risk patients to be followed at an institution where VAD is available. In contrast, 3 of 4 patients with status 2 who eventually received VAD implantation had plasma BNP $<740 \mathrm{pg} / \mathrm{ml}$. The exacerbation of HF was relatively gradual among them and LVAD could be successfully implanted after they were inotrope dependent for a certain time period. It is of note that BNP level can stratify different time frames of HF progression.

Among 10 deceased patients, 4 out-hospital patients died suddenly due to Vf. Two patients had already received CRT$\mathrm{D}$, and they had been assigned "modifier A", the significance of which we previously proposed. ${ }^{27}$ Patents with modifier A cannot be rescued only by CRT-D because of the deterioration of hemodynamics during electrical storm. Such patients may also be good candidates for MCS considering its advantage in avoidance of sudden death due to hemodynamic deterioration following fatal ventricular tachyarrhythmia, although sometimes these patients appear too well to receive MCS.

Guidelines state that CRT may be considered for ambulatory NYHA IV patients but not indicated for those who are inotrope dependent. ${ }^{28}$ Nevertheless, CRT-D is often indicated for patients with advanced HF before VAD treatment partly because of hesitation in VAD implantation. In agreement with this, 56 patients $(60.9 \%)$ had received CRT-D before review board approval among those who had not had VAD treatment. CRT$\mathrm{D}$, however, was not significantly associated with better 4-year survival according to Cox regression analysis. Furthermore, CRT-D was not sufficient to rescue patients with modifier A. Therefore, the evidence-based indication for CRT-D should be more strictly observed in order to minimize the percentage of non-responders as well as to save medical expenses.

Recently, the Medical Arm of INTERMACS (MEDAMACS) and the randomized evaluation of VAD intervention before inotropic therapy (REVIVE-IT) have been conducted in the USA to assess medically treated patients with profile 4-6 who might become candidates for VAD treatment. ${ }^{8,29}$ The results would provide a reasonable indication for MCS in less sick patients.

\section{Study Limitations}

This study was conducted retrospectively at a single center, and consequently included a limited number of patients. The present institutional review board, however, is one of the major committees in Japan and a number of patients (62 patients; $33.9 \%$ ) were referred from other institutes. Nevertheless, data from all HTx centers in Japan would definitely strengthen statistical power.

Only 4 VAD implants in the status 2 group were carried out, and we could not analyze the effects of VAD implantation on prognosis. Although the impact of VAD implantation on mortality appears to be clear in the combined group of status 1 and status 2, the survival benefit of VAD implantation in status 2 patients was not able to be demonstrated in this study.

\section{Conclusions}

Prognosis in status 2 patients was as poor as those dependent on inotrope infusion or VAD treatment because of out-ofhospital sudden death without MCS. Status 2 patients with high 
plasma BNP may be good candidates for CF VAD therapy.

\section{Acknowledgments}

Grant-in-Aid from Fukuda Foundation for medical Technology to K.K. The authors have no conflict of interest.

\section{References}

1. Lindenfeld J, Feldman AM, Saxon L, Boehmer J, Carson P, Ghali JK, et al. Effects of cardiac resynchronization therapy with or without a defibrillator on survival and hospitalizations in patients with New York Heart Association class IV heart failure. Circulation 2007; 115: 204-212.

2. Kitamura S. Heart transplantation in Japan: A critical appraisal for the results and future prospects. Gen Thorac Cardiovasc Surg 2012; 60: $639-644$

3. Imamura T, Kinugawa K, Shiga T, Endo M, Kato N, Inaba T, et al. Preoperative levels of bilirubin or creatinine adjusted by age can predict their reversibility after implantation of left ventricular assist device. Circ J 2013; 77: 96-104.

4. Suwa H, Seguchi O, Fujita T, Murata Y, Hieda M, Watanabe T, et al Paracorporeal ventricular assist device as a bridge to transplant candidacy in the era of implantable continuous-flow ventricular assist device. J Artif Organs 2014; 17: 16-22.

5. Kinugawa K. How to treat stage $\mathrm{D}$ heart failure: When to implant left ventricular assist devices in the era of continuous flow pumps. Circ J 2011; 75: 2038-2045.

6. Nakatani T. Heart transplantation. Circ J 2009; 73(Suppl A): A55-A60.

7. Slaughter MS. UNOS status of heart transplant patients supported with a left ventricular assist device: Is it time to reconsider the status criteria? Tex Heart Inst J 2011; 38: 549-551.

8. Kirklin JK, Naftel DC, Kormos RL, Stevenson LW, Pagani FD, Miller MA, et al. Fifth INTERMACS annual report: Risk factor analysis from more than 6,000 mechanical circulatory support patients. $J$ Heart Lung Transplant 2013; 32: 141-156.

9. Imamura T, Kinugawa K, Shiga T, Endo M, Kato N, Inaba T, et al. Novel risk scoring system with preoperative objective parameters gives a good prediction of 1-year mortality in patients with a left ventricular assist device. Circ J 2012; 76: 1895-1903.

10. Yoshioka D, Sakaguchi T, Saito S, Miyagawa S, Nishi H, Yoshikawa $\mathrm{Y}$, et al. Predictor of early mortality for severe heart failure patients with left ventricular assist device implantation: Significance of INTERMACS level and renal function. Circ J 2012; 76: 1631 - 1638

11. Rao V, Oz MC, Flannery MA, Catanese KA, Argenziano M, Naka Y. Revised screening scale to predict survival after insertion of a left ventricular assist device. J Thorac Cardiovasc Surg 2003; 125: 855862.

12. Knaus WA, Draper EA, Wagner DP, Zimmerman JE. APACHE II: A severity of disease classification system. Crit Care Med 1985; 13: $818-829$.

13. Lietz K, Long JW, Kfoury AG, Slaughter MS, Silver MA, Milano $\mathrm{CA}$, et al. Outcomes of left ventricular assist device implantation as destination therapy in the post-REMATCH era: Implications for patient selection. Circulation 2007; 116: 497-505.

14. Levy WC, Mozaffarian D, Linker DT, Sutradhar SC, Anker SD, Cropp $\mathrm{AB}$, et al. The Seattle Heart Failure Model: Prediction of survival in heart failure. Circulation 2006; 113: 1424-1433.

15. Holman WL, Kormos RL, Naftel DC, Miller MA, Pagani FD, Blume E, et al. Predictors of death and transplant in patients with a mechanical circulatory support device: A multi-institutional study. J Heart
Lung Transplant 2009; 28: 44-50.

16. Toda K, Fujita T, Kobayashi J, Shimahara Y, Kitamura S, Seguchi $\mathrm{O}$, et al. Impact of preoperative percutaneous cardiopulmonary support on outcome following left ventricular assist device implantation. Circ J 2012; 76: 88-95.

17. Hori M, Nagai R, Izumi T, Matsuzaki M. Efficacy and safety of bisoprolol fumarate compared with carvedilol in Japanese patients with chronic heart failure: Results of the randomized, controlled, doubleblind, Multistep Administration of bisoprolol IN Chronic Heart Failure II (MAIN-CHF II) study. Heart Vessels 2014; 29: 238-247.

18. McKelvie RS, Yusuf S, Pericak D, Avezum A, Burns RJ, Probstfield $\mathrm{J}$, et al. Comparison of candesartan, enalapril, and their combination in congestive heart failure: Randomized evaluation of strategies for left ventricular dysfunction (RESOLVD) pilot study. The RESOLVD Pilot Study Investigators. Circulation 1999; 100: 1056-1064.

19. Moazami N, Shah NR, Ewald GA, Geltman EM, Moorhead SL, Pasque MK. Should UNOS Status 2 patients undergo transplantation? Heart Surg Forum 2006; 9: E823-E827.

20. Gheorghiade M, Rossi JS, Cotts W, Shin DD, Hellkamp AS, Pina IL, et al. Characterization and prognostic value of persistent hyponatremia in patients with severe heart failure in the ESCAPE Trial. Arch Intern Med 2007; 167: 1998-2005.

21. Damman K, Valente MA, Voors AA, O'Connor CM, van Veldhuisen DJ, Hillege HL. Renal impairment, worsening renal function, and outcome in patients with heart failure: An updated meta-analysis. Eur Heart J 2014; 35: 455-469.

22. Aspromonte N, Valle R, Peacock WF, Vanderheyden M, Maisel A. Inpatient monitoring and prognostic importance of B-type natriuretic peptide. Congest Heart Fail 2008; 14(4 Suppl 1): 30-34.

23. Flint KM, Matlock DD, Sundareswaran KS, Lindenfeld J, Spertus JA, Farrar DJ, et al. Pre-operative health status and outcomes after continuous-flow left ventricular assist device implantation. J Heart Lung Transplant 2013; 32: 1249-1254.

24. Iwashima Y, Yanase M, Horio T, Seguchi O, Murata Y, Fujita T, et al Serial changes in renal function as a prognostic indicator in advanced heart failure patients with left ventricular assist system. Ann Thorac Surg 2012; 93: 816-823.

25. Boyle AJ, Ascheim DD, Russo MJ, Kormos RL, John R, Naka Y, et al. Clinical outcomes for continuous-flow left ventricular assist device patients stratified by pre-operative INTERMACS classification. J Heart Lung Transplant 2011; 30: 402-407.

26. Kato TS, Collado E, Khawaja T, Kawano Y, Kim M, Farr M, et al. Value of peak exercise oxygen consumption combined with B-type natriuretic peptide levels for optimal timing of cardiac transplantation. Circ Heart Fail 2013; 6: 6-14.

27. Imamura T, Kinugawa K, Shiga T, Endo M, Inaba T, Maki H, et al. Early decision for a left ventricular assist device implantation is necessary for patients with modifier A. J Artif Organs 2012; 15: $301-$ 304.

28. Hunt SA, Abraham WT, Chin MH, Feldman AM, Francis GS, Ganiats TG, et al. Focused update incorporated into the ACC/AHA 2005 Guidelines for the Diagnosis and Management of Heart Failure in Adults: A Report of the American College of Cardiology Foundation/ American Heart Association Task Force on Practice Guidelines Developed in Collaboration With the International Society for Heart and Lung Transplantation. J Am Coll Cardiol 2009; 53(15): e1 -e90, doi: 10.1016/j.jacc.2008.11.013.

29. Baldwin JT, Mann DL. NHLBI's program for VAD therapy for moderately advanced heart failure: The REVIVE-IT pilot trial. $J$ Card Fail 2010; 16: 855-858. 